\title{
Prevalence of periodontal disease in tobacco using adult population of Rishikesh and their quitting behaviour
}

\author{
Himanshu Aeran ${ }^{1, *}$, Amrinder Tuli ${ }^{2}$, Shivani $\mathrm{Abrol}^{3}$, Suhani Gupta ${ }^{4}$ \\ ${ }^{1}$ Director Principal and Head, ${ }^{2}$ Professor, ${ }^{3,4}$ PG Student, ${ }^{1,2,3}$ Dept. of Prosthodontics \& Oral Implantology, ${ }^{4}$ Dept. of Oral and \\ Maxillofacial Radiology, Seema Dental College \& Hospital, Rishikesh, Uttarakhand, India
}

*Corresponding Author: Himanshu Aeran

Email: drhimanu@yahoo.com

\begin{abstract}
Aim and Objective: 1. To know the prevalence of smoking and smokeless tobacco use; 2. Its impact on periodontal disease; 3. The quitting behavior in a population of Rishikesh.

Materials and Methods: Present study was conducted in Seema dental college and hospital Rishikesh. A pre-structured and pretested schedule was used for collection of relevant data pertaining to smoking form of tobacco. The socio-demographic variables were collected. Subjects were interviewed about their smoking status, different forms of smoking product used and periodontal parameters recorded.

Results: A total of 2012 subjects were studied. 220 out of 2012 were found to be exclusive tobacco users. 212 were males and 8 were females. More smokers were found to be males than females and the difference was found to be statistically significant ( $\mathrm{p}<0.05)$. Total prevalence of tobacco use is $10.4 \%$.Current tobacco users by their previous attempts to quit in which $66.7 \%$ current smokers and $24.1 \%$ smokeless tobacco users and $9.3 \%$ both users have attempted to quit in the past 3 months.

Conclusion: Prevalence of tobacco use more in males than females. Periodontal disease severity was higher in tobacco users. The desire to quit tobacco using was also found to be more among males as compared to female smokers.
\end{abstract}

Keywords: Tobacco, Periodontal status, Quitting.

\section{Introduction}

Tobacco kills one person every six seconds and its third to half of all people who use it, on average 15 years prematurely. Today, tobacco use causes 1 in 10 deaths among adults worldwide - more than five million people a year. By 2030, unless urgent action is taken, tobacco's annual death toll will rise to more than eight million. If current trends continue unchecked, it is estimated that around 500 million people alive today will be killed by tobacco. During this twenty-first century, tobacco could kill up to one billion people. Most tobacco users want to quit but will be unable to because of their dependence on a highly addictive substance. ${ }^{1}$

Almost $35 \%$ of men in developed countries and $50 \%$ of men in developing countries smoke; while $22 \%$ of women in developed countries and $9 \%$ of women in developing countries smoke. More than $80 \%$ of the world's smokers live in low- and middle-income countries. Every day, 80,000-100,000 young people around the world become addicted to tobacco. ${ }^{2}$ Cigarette smoking and use of other tobacco products is increasing in the developing world due to rise of tobacco industry and population growth. ${ }^{3}$

Tobacco use in any form has the potential to profoundly alter the systemic and oral health of the individual. The use of tobacco is associated with a wide spectrum of disease including stroke, coronary artery disease, peripheral artery disease, gastric ulcer and cancers of mouth, larynx, esophagus, pancreas, bladder and uterine cervix. It is also a major cause of chronic obstructive pulmonary disease and risk factor for low birth weight babies. It has also been recognized to be a significant risk factor for periodontitis affecting the prevalence, extent and severity of disease. Tobacco use is associated with increased pocket depths, loss of periodontal attachment, alveolar bone and higher rate of tooth loss. Chronic periodontitis is one of the common dental diseases with high tooth mortality as well as morbidity. Majority of the population is suffering from moderate grade of periodontitis that initiates at an early age, and clinical manifestations of the disease with noticeable morbidity start after 35 years of age, which if left untreated will ultimately result in loss of tooth. ${ }^{4}$

Hence the present study was conducted with the following aims and objectives:

1. To know the prevalence of smoking and smokeless tobacco use

2. Its impact on periodontal disease

3. The quitting behavior in a population of Rishikesh.

\section{Materials and Methods}

The present cross sectional study was conducted in Seema Dental College and Hospital, Rishikesh. The study population comprised of all persons more than 15 years. The data was collected for a period of three months i.e. October to December 2017 in the department of Oral Medicine and Radiology, Seema Dental College and Hospital, Rishikesh. The study was approved by institutional ethical committee and informed verbal consent was obtained from the study subjects. A pre-structured and pre-tested schedule was used for collection of relevant data pertaining to smoking form of tobacco. The socio-demographic 
variables collected were age, sex, educational attainment and occupation of the participant and income of the family. Subjects were interviewed about their smoking status. Details on the different forms of smoking product used, including cigarette, bidi and tobacco were obtained from the smokers. Informed consent was obtained from the study subjects and responses were recorded on data recording form in the department of Periodontology.

\section{Results}

A total of 2012 subjects were studied. 220 out of 2012 were found to be exclusive tobacco users. 140 using only smoking form of tobacco while 58 subjects were using smokeless tobacco and 22 subjects using both forms of tobacco. Table 1 shows that among 220 current smokers, 212 were males and 8 were females. More smokers were found to be males than females and the difference was found to be statistically significant $(\mathrm{p}<0.05)$. Table 2 shows the current tobacco users by their previous attempts to quit in which $66.7 \%$ current smokers and $24.1 \%$ smokeless tobacco users and $9.3 \%$ both users have attempted to quit in the past 3 months. Table 3 shows the age specific prevalence of cur-rent smoking which reveals that the prevalence of smoking, tobacco chewing and both forms highest in 21-30 age group.

22 Out of 244 tobacco users either smokeless or smoking form, desires to quit that previously have very high addiction rate thereby giving the overall prevalence of $1.04 \%$ respectively. The reason behind the desire for quitting tobacco was awareness of addiction, financial reason, responsibility, family pressure, opinion of others, oral health detioration.

Table 1

\begin{tabular}{|c|c|c|c|c|c|}
\hline \multicolumn{5}{|c|}{ Gender } & \multirow[t]{2}{*}{ Total } \\
\hline & & & Female & Male & \\
\hline \multirow{6}{*}{ Habit } & \multirow[t]{2}{*}{ Smoking } & Count & 3 & 137 & 140 \\
\hline & & $\%$ within gender & $37.5 \%$ & $64.6 \%$ & $63.6 \%$ \\
\hline & \multirow[t]{2}{*}{ Chewing } & Count & 5 & 53 & 58 \\
\hline & & $\%$ within gender & $62.5 \%$ & $25.0 \%$ & $26.4 \%$ \\
\hline & \multirow[t]{2}{*}{ Both } & Count & 0 & 22 & 22 \\
\hline & & $\%$ within gender & $0.0 \%$ & $10.4 \%$ & $10.0 \%$ \\
\hline \multirow{2}{*}{\multicolumn{2}{|c|}{ Total }} & Count & 8 & 212 & 220 \\
\hline & & $\%$ within gender & $100.0 \%$ & $100.0 \%$ & $100.0 \%$ \\
\hline \multicolumn{4}{|c|}{ Chi-Square Tests } & & \\
\hline & Value & df & $\begin{array}{c}\mathrm{P} \text { value ( } \text { significant if } \\
<0.05)\end{array}$ & & \\
\hline Pearson Chi-Square & 5.833 & 2 & .054 & & \\
\hline $\mathrm{N}$ of Valid Cases & 220 & & & & \\
\hline
\end{tabular}

Table 2

\begin{tabular}{|c|c|c|c|c|c|c|c|}
\hline \multicolumn{8}{|c|}{ Crosstab } \\
\hline & & & & & \multicolumn{2}{|c|}{$\begin{array}{c}\text { Previous quitting } \\
\text { attempt }\end{array}$} & \multirow[t]{2}{*}{ Total } \\
\hline & & & & & No & Yes & \\
\hline \multirow[t]{6}{*}{ Habit } & \multirow[t]{2}{*}{ Smoking } & \multicolumn{3}{|r|}{ Count } & 32 & 108 & 140 \\
\hline & & \multicolumn{3}{|c|}{$\%$ within Previous Quitting Attempt } & $55.2 \%$ & $66.7 \%$ & $63.6 \%$ \\
\hline & \multirow[t]{2}{*}{ Chewing } & \multicolumn{3}{|c|}{ Count } & 19 & 39 & 58 \\
\hline & & \multicolumn{3}{|c|}{$\%$ within Previous Quitting Attempt } & $32.8 \%$ & $24.1 \%$ & $26.4 \%$ \\
\hline & \multirow[t]{2}{*}{ Both } & \multicolumn{3}{|c|}{+2} & 7 & 15 & 22 \\
\hline & & \multicolumn{3}{|c|}{$\%$ within Previous Quitting Attempt } & $12.1 \%$ & $9.3 \%$ & $10.0 \%$ \\
\hline \multirow{2}{*}{\multicolumn{2}{|c|}{ Total }} & & & Count & 58 & 162 & 220 \\
\hline & & & thin 1 & ous Quitting Attempt & $100.0 \%$ & $100.0 \%$ & $100.0 \%$ \\
\hline \multicolumn{5}{|c|}{ Chi-Square Tests } & & & \\
\hline & & Value & & $\begin{array}{c}\mathrm{P} \text { value (significant if } \\
<0.05)\end{array}$ & & & \\
\hline \multicolumn{2}{|c|}{$\begin{array}{l}\text { Pearson Chi- } \\
\text { Square }\end{array}$} & 2.446 & 2 & .294 & & & \\
\hline \multicolumn{2}{|c|}{$\mathrm{N}$ of Valid Cases } & 220 & & & & & \\
\hline
\end{tabular}


Table 3

\begin{tabular}{|c|c|c|c|c|c|c|}
\hline \multicolumn{7}{|c|}{ Age * habit } \\
\hline & & & \multicolumn{3}{|c|}{ Habit } & \multirow[t]{2}{*}{ Total } \\
\hline & & & Smoking & Chewing & Both & \\
\hline \multirow[t]{14}{*}{ Age } & \multirow[t]{2}{*}{$<=20$} & Count & 13 & 6 & 1 & 20 \\
\hline & & $\%$ within HABIT & $9.3 \%$ & $10.3 \%$ & $4.5 \%$ & $9.1 \%$ \\
\hline & \multirow[t]{2}{*}{$21-30$} & Count & 38 & 19 & 11 & 68 \\
\hline & & $\%$ within HABIT & $27.1 \%$ & $32.8 \%$ & $50.0 \%$ & $30.9 \%$ \\
\hline & \multirow[t]{2}{*}{$31-40$} & Count & 22 & 17 & 2 & 41 \\
\hline & & $\%$ within HABIT & $15.7 \%$ & $29.3 \%$ & $9.1 \%$ & $18.6 \%$ \\
\hline & \multirow[t]{2}{*}{$41-50$} & Count & 26 & 8 & 5 & 39 \\
\hline & & $\%$ within HABIT & $18.6 \%$ & $13.8 \%$ & $22.7 \%$ & $17.7 \%$ \\
\hline & \multirow[t]{2}{*}{$51-60$} & Count & 27 & 5 & 3 & 35 \\
\hline & & $\%$ within HABIT & $19.3 \%$ & $8.6 \%$ & $13.6 \%$ & $15.9 \%$ \\
\hline & \multirow[t]{2}{*}{$61-70$} & Count & 14 & 1 & 0 & 15 \\
\hline & & $\%$ within HABIT & $10.0 \%$ & $1.7 \%$ & $0.0 \%$ & $6.8 \%$ \\
\hline & \multirow[t]{2}{*}{$>70$} & Count & 0 & 2 & 0 & 2 \\
\hline & & \% within HABIT & $0.0 \%$ & $3.4 \%$ & $0.0 \%$ & $0.9 \%$ \\
\hline \multirow{2}{*}{\multicolumn{2}{|c|}{ Total }} & Count & 140 & 58 & 22 & 220 \\
\hline & & $\%$ within HABIT & $100.0 \%$ & $100.0 \%$ & $100.0 \%$ & $100.0 \%$ \\
\hline \multicolumn{5}{|c|}{ Chi-Square Tests } & & \\
\hline & & Value & $\mathrm{df}$ & $\mathrm{P}$ value & & \\
\hline Pears & hi-Square & 24.427 & 12 & .018 & & \\
\hline $\mathrm{No}$ & lid Cases & 220 & & & & \\
\hline
\end{tabular}

Table 4: Independent $t$ test for comaprisn of the PI, probing depth age between the people who quit and didn't

\begin{tabular}{|c|c|c|c|c|c|c|c|}
\hline & $\begin{array}{c}\text { Previous } \\
\text { Quitting Attempt }\end{array}$ & $\mathbf{N}$ & Mean & $\begin{array}{c}\text { Std. } \\
\text { Deviation }\end{array}$ & $\mathbf{t}$ & df & P Value \\
\hline \multirow[t]{2}{*}{ Plaque index } & No & 58 & 1.487931 & 0.40091 & \multirow[t]{2}{*}{-2.91} & \multirow[t]{2}{*}{218} & \multirow[t]{2}{*}{0.004} \\
\hline & Yes & 162 & 1.675926 & 0.429474 & & & \\
\hline \multirow{2}{*}{ Gingival index } & No & 58 & 1.65 & 0.315255 & \multirow{2}{*}{$\begin{array}{c}- \\
2.943\end{array}$} & \multirow[t]{2}{*}{135.71} & \multirow[t]{2}{*}{0.004} \\
\hline & Yes & 162 & 1.80679 & 0.42691 & & & \\
\hline \multirow[t]{2}{*}{ Probing depth } & No & 58 & 3.81 & 1.235 & \multirow{2}{*}{$\begin{array}{c}- \\
3.717\end{array}$} & \multirow[t]{2}{*}{218} & \multirow[t]{2}{*}{$<0.001$} \\
\hline & Yes & 162 & 4.57 & 1.364 & & & \\
\hline \multirow[t]{2}{*}{ Age } & No & 58 & 24.14 & 7.139 & \multirow{2}{*}{$\begin{array}{c}- \\
13.45\end{array}$} & \multirow[t]{2}{*}{191.21} & \multirow[t]{2}{*}{$<0.001$} \\
\hline & Yes & 162 & 43.45 & 13.85 & & & \\
\hline
\end{tabular}

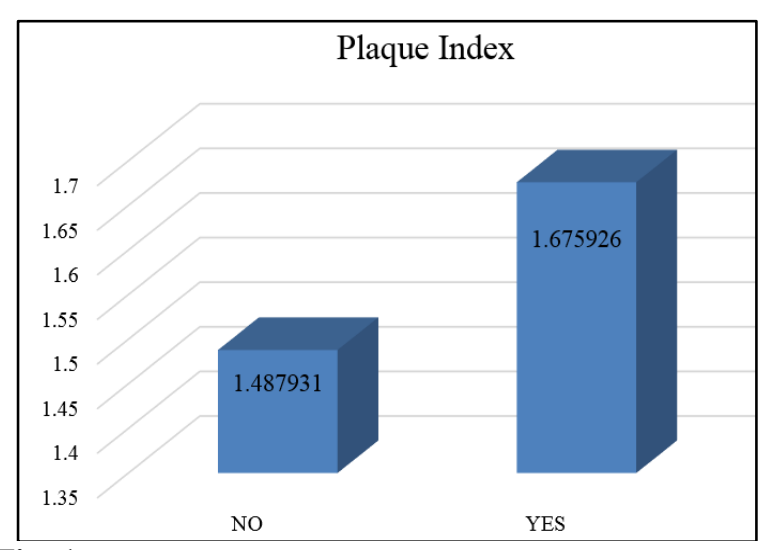

Fig. 1

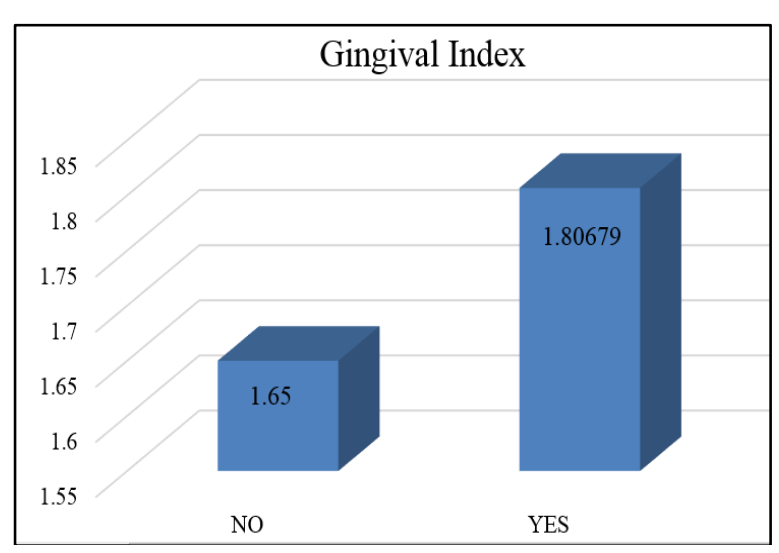

Fig. 2 


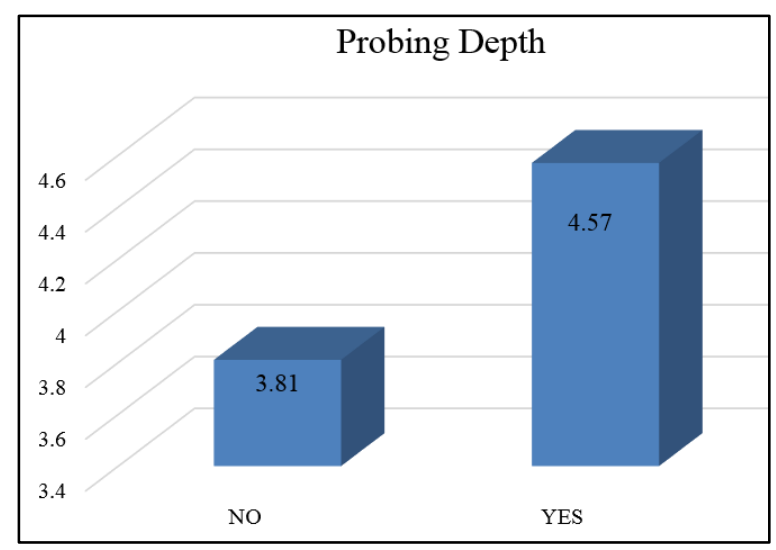

Fig. 3

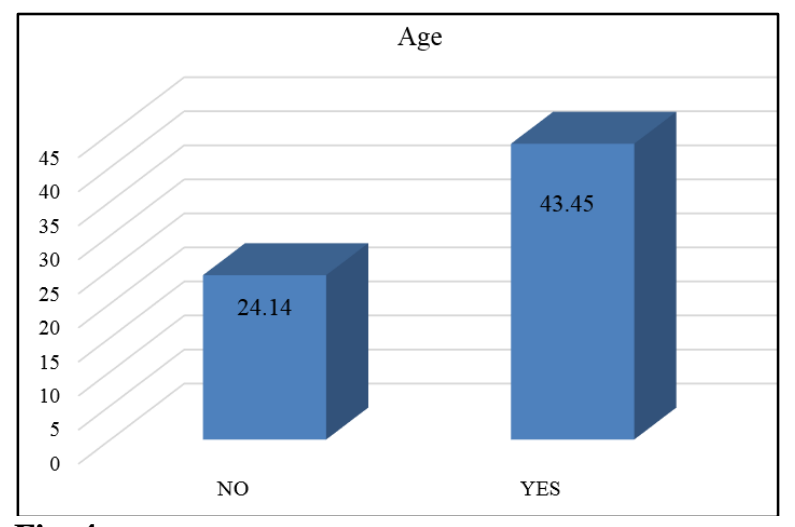

Fig. 4

Comparison of the PLAQUE INDEX between the two groups shows that PLAQUE INDEX is higher in YES group with a $t$ value of -2.91 and is statistically significant with a $\mathrm{p}$ value of 0.004

Comparison of the GINGIVAL INDEX between the two groups shows that GINGIVAL INDEX is higher in YES group with a $t$ value of -2.943 and is statistically significant with a $\mathrm{p}$ value of 0.004

Comparison of the PROBING DEPTH between the two groups shows that PROBING DEPTH is higher in YES group with a t value of -3.717 and is statistically significant with a $\mathrm{p}$ value of $<0.001$

Comparison of the AGE between the two groups shows that AGE is higher in YES group with a $t$ value of -13.447 and is statistically significant with a $p$ value of $<0.001$

\section{Discussion}

In the study $1.04 \%$ of the current tobacco users had attempted to quit in the past 3 months. According to GATS Uttarakhand (2009-10), about 30\% smokers made an attempt to quit smoking in the past 12 months. Ansari et al in their study reported that more than half $(55 \%)$ of the smokers had attempted to quit smoking in the past one year.

In the present study, the percentage of current tobacco users who made an attempt to quit tobacco was $1.04 \%$, as compared to $35.4 \%$ and $37.8 \%$ found according to GATS India (2009-10) and GATS Uttarakhand (2009-10) respectively. ${ }^{7}$ Jindal et al reported the prevalence of current smoking to be $14 \%$ and $15.6 \%$ respectively. ${ }^{8}$ Narayan et al found increased smoking prevalence among those aged 35-44 years and lowest in those aged 55-64 years. ${ }^{9}$ In our study, majority of current smokers initiated the habit of smoking at or before 19 years of age which is slightly higher as compared to study done by Bhimarasetty et al where $41.2 \%$ initiated it before attaining the age of 19 years. Which is comparable to the findings of GATS India (2009-10), where $40.3 \%$ of the respondents initiated smoking after 19 years. ${ }^{7}$

Danish Imtiyaz et al assess the prevalence and factors influencing smoking tobacco use among rural Community of Dehradun and found that smoking was found to be more prevalent in males as compared to females and also showed a consistent rise with the increasing age group. ${ }^{10}$

\section{Conclusion}

The findings from this study highlighted the need to increase awareness about the health effects of smoking and smokeless tobacco use to encourage quitting, particularly in rural areas, where levels of education and knowledge about health are lower and where health care services are scarcely available.

The above study revealed that the prevalence of smoking tobacco use was quite prevalent among the rural population which is a matter of concern and will contribute to the disease burden already existing due to nutrition-related illness and communicable diseases in this section of population. There is evidence from the study suggesting the increasing trend of smoking tobacco use with advancing age thereby implying that tobacco control policies should strategically focus on all age groups particularly on those greater than fifty years of age.

\section{References}

1. World Health Organization. WHO report on the global tobacco epidemic, 2008. Geneva: World Health Organization; 2008:1-342.

2. The World Bank. Curbing the Epidemic: Governments and the Economics of Tobacco Control. Washington, DC: World Bank Publications; 1999.

3. World Health Organization. WHO report on the Global Tobacco Epidemic 2011: Warning about the dangers of tobacco. Geneva: WHO; 2011.

4. Brown LJ, Loe H. Prevalence, extent, severity and progression of periodontal disease. Periodontol. 2000. 1993;2:57-71.

5. Ministry of Health and Family Welfare, Government of India. Global Adult Tobacco Survey: India Report 200910. New Delhi, India, 2010. Available from: http://whoindia.org/EN/Section 20/ Section 25_1861.htm.

6. El Ansari W, Stock C. Factors associated with smoking, quit attempts and attitudes towards total smoking bans at university: a survey of seven universities in England, Wales and Northern Ireland. Asian Pac J Cancer Prev. 2012;13(2):705-14. 
7. Ministry of Health and Family Welfare, Government of India. Global Adult Tobacco Survey: India Report 200910. New Delhi, India, 2010. Available from: http://whoindia.org/EN/Section 20/ Section 25_1861.htm.

8. Jindal S, Aggarwal A, Chaudhry K, Chhabra S, D Souza $\mathrm{G}$, Gupta D et al. Tobacco smoking in India: prevalence, quit-rates and respiratory morbidity. Indian J Chest Dis Allied Sci. 2006;48(1):37

9. Narayan KM, Chadha SL, Hanson RL, Tandon R, Shekhawat S, Fernandes RJ et al. Prevalence and patterns of smoking in Delhi: Cross sectional study. BMJ. 1996;312:1576-9.

10. Imtiyaz D. A study on prevalence and pattern of smoking among rural population in Dehradun district of Uttarakhand. Indian J Community Med. 2014;5:440-443. 